\title{
Human cholesterol 7 $\alpha$-hydroxylase (CYP7A1) deficiency has a hypercholesterolemic phenotype
}

\author{
Clive R. Pullinger, ${ }^{1}$ Celeste Eng, ${ }^{1}$ Gerald Salen,, ${ }^{2,3}$ Sarah Shefer, ${ }^{2}$ Ashok K. Batta, ${ }^{2}$ \\ Sandra K. Erickson, ${ }^{4,5}$ Andrea Verhagen, ${ }^{1}$ Christopher R. Rivera, ${ }^{4}$ Sean J. Mulvihill, ${ }^{6}$ \\ Mary J. Malloy, ${ }^{1,4}$ and John P. Kane $e^{1,4,7}$ \\ ${ }^{1}$ Cardiovascular Research Institute, University of California, San Francisco, San Francisco, California, USA \\ ${ }^{2}$ Department of Medicine and Liver Center, University of Medicine and Dentistry of New Jersey - New Jersey Medical School, \\ Newark, New Jersey, USA \\ ${ }^{3}$ Veterans Affairs Medical Center, East Orange, New Jersey, USA \\ ${ }^{4}$ Department of Medicine, University of California, San Francisco, San Francisco, California, USA \\ ${ }^{5}$ Veterans Affairs Medical Center, San Francisco, California, USA \\ ${ }^{6}$ Department of Surgery, University of Utah, Salt Lake City, Utah, USA \\ ${ }^{7}$ Department of Biochemistry and Biophysics, University of California, San Francisco, San Francisco, California, USA
}

Bile acid synthesis plays a critical role in the maintenance of mammalian cholesterol homeostasis. The CYP7A1 gene encodes the enzyme cholesterol $7 \alpha$-hydroxylase, which catalyzes the initial step in cholesterol catabolism and bile acid synthesis. We report here a new metabolic disorder presenting with hyperlipidemia caused by a homozygous deletion mutation in CYP7A1. The mutation leads to a frameshift (L413fsX414) that results in loss of the active site and enzyme function. High levels of LDL cholesterol were seen in three homozygous subjects. Analysis of a liver biopsy and stool from one of these subjects revealed double the normal hepatic cholesterol content, a markedly deficient rate of bile acid excretion, and evidence for upregulation of the alternative bile acid pathway. Two male subjects studied had hypertriglyceridemia and premature gallstone disease, and their LDL cholesterol levels were noticeably resistant to 3-hydroxy-3-methylglutaryl-coenzyme A reductase inhibitors. One subject also had premature coronary and peripheral vascular disease. Study of the kindred, which is of English and Celtic background, revealed that individuals heterozygous for the mutation are also hyperlipidemic, indicating that this is a codominant disorder.

J. Clin. Invest. 110:109-117 (2002). doi:10.1172/JCI200215387.

\section{Introduction}

Central to the development of atherosclerosis is infiltration of cholesterol-rich lipoproteins into the artery wall. Elevated levels of atherogenic LDL increase risk. Thus, understanding mechanisms by which LDL levels become elevated is important for prevention and treatment of atherosclerosis. Whereas in the population at large the level of LDL results from the contribution of several genetic trait loci, there are four specific monogenic disorders in which elevated levels of LDL are associated with premature atherosclerotic heart disease (1). These are familial hypercholesterolemia (linked to the LDL receptor (LDLR) gene) (2); familial ligand-defective apoB-100

Received for publication March 4, 2002, and accepted in revised form May 28, 2002

Address correspondence to: Clive R. Pullinger, Cardiovascular Research Institute, University of California, San Francisco, San Francisco, California 94143-0130, USA.

Phone: (415) 476-5938, or (415) 476-1155; Fax: (415) 502-5658;

E-mail: clivep@itsa.ucsf.edu.

Conflict of interest: No conflict of interest has been declared.

Nonstandard abbreviations used: LDL receptor (LDLR); 3-hydroxy-3-methylglutaryl-coenzyme A (HMG-CoA); denaturing gradient gel electrophoresis (DGGE); University of California, San Francisco (UCSF); body mass index (BMI); farnesoid X receptor (FXR). (linked to $A P O B)$ (3); autosomal recessive hypercholesterolemia (linked to $A R H$ ) (4); and sitosterolemia (linked to either $A B C G 5$ or $A B C G 8)(5,6)$. We hypothesized that an important additional candidate is the CYP7A1 gene (which encodes the enzyme cholesterol $7 \alpha$-hydroxylase) to which no major monogenic disorders of lipid metabolism have been ascribed. This hepato-specific member of the cytochrome P450 mixed-function oxidase superfamily initiates the major pathway for catabolism of cholesterol, the synthesis of bile acids (7). The hepato-biliary system is the primary pathway for cholesterol excretion. We hypothesized that a deficiency of CYP7A1 would cause a decrease in bile acid production and accumulation of cholesterol in the liver, leading to downregulation of LDL receptors and consequent hypercholesterolemia. The magnitude of this effect would depend on the extent to which the alternative bile acid pathway could overcome the lack of CYP7A1. Another element of the phenotype of CYP7A1 deficiency might be susceptibility to cholesterol gallstones due to inability to solubilize cholesterol in bile salt mixed micelles. In addition, because the cholesterol content of the liver would be expected to be elevated, the efficiency of 3-hydroxy-3methylglutaryl-coenzyme A (HMG-CoA) reductase inhibitors in inducing LDL receptors, and thus decreas- 
ing levels of LDL, might be impaired. CYP7A1 mutations shown to elevate LDL would identify CYP7A1 deficiency as the fifth monogenic disorder associated with elevated levels of LDL.

After cloning of the human gene $(8,9)$, several polymorphisms were identified and shown to be associated with LDL levels in the population (10-12). Overexpression of CYP7A1 in hamsters by adenovirus-mediated gene transfer led to a large decrease in the level of LDL (13). Transgenic mice overexpressing CYP7A1 were protected from diet-induced atherosclerosis and formation of gallstones (14). Targeted gene disruption in mice yielded a complex phenotype with conflicting reports concerning the effect on serum lipids $(7,15,16)$.

Based on the prediction that CYP7A1 mutations would be associated with hypercholesterolemia and resistance to HMG-CoA reductase inhibitors, we screened patients from the Lipid Clinic at the University of California, San Francisco (UCSF) and control subjects for CYP7A1 gene mutations using denaturing gradient gel electrophoresis (DGGE). A patient with significant hyperlipidemia and profound resistance to HMG-CoA reductase inhibitors was found to carry a CYP7A1 null mutation. We examined this patient's family to determine whether the mutation cosegregated with the disease. The impact of the mutation on fecal bile acid composition and excretion and its effect on relevant hepatic enzyme activities were measured. Activity of the mutant gene product was determined by in vitro expression.

\section{Methods}

Patient selection and sample collection. Genomic DNA was routinely prepared from whole blood obtained from patients in the Lipid Clinic of UCSF (17). Samples were selected for analysis on the basis of the patient having either a plasma level of LDL cholesterol above 200 $\mathrm{mg} / \mathrm{dl}$ or resistance to HMG-CoA reductase inhibitors. Further samples were collected from all available members of the proband's family. The protocols were approved by the UCSF Committee on Human Research. Informed consent was obtained from all subjects for DNA isolation and plasma and stool collections. Children were included with parental consent. Patient IV-17 consented to a liver biopsy. Material from three normal livers was obtained from the liver procurement program at the University of Minnesota Medical School.

Mutation detection. DGGE was performed as described previously (18). The coding region of exon 6 was amplified using GC-clamped primers 5 '-cgccegcegcgeccegcgcccgtccegecgeccecgCTTAGCTCATTAAGCTCCTGTTC- $3^{\prime}$ and $5^{\prime}$-cgcccgccgcgeccegcgeccgtccegccgcccccgCCACCACTAAATGCATTTGTC-3'. Prior to DGGE, samples were digested with MboI. Those showing gel shift patterns were directly sequenced using an ABI PRISM 377 sequencer (Perkin-Elmer Applied Biosystems, Foster City, California, USA). The 1302-1303delTT mutation was confirmed by TaqI digestion of both the exon 6 amplicon and full-length cDNA produced by RT-PCR and nested
PCR (19), using liver RNA from patient IV-17. For RT-PCR we used primers $5^{\prime}$-CTTCCTCAGAGATTTTGGCCTAGATTTGC- $3^{\prime}$ and $5^{\prime}$-CTGTGTGGTGAGGGTGTTCTGCAGTCCTG- $3^{\prime}$ and for the nested PCR primers $5^{\prime}$-TTGGgCTAGcTTTGCAAAATGATGACCAC- $3^{\prime}$ and $5^{\prime}$-TCATCTcGaGTCCTCTTATTCCAGCCATG-3'.

CYP7A1 expression and enzyme assay. RT-PCR-generated cDNA from the control subject and patient RNA (see above) was gel purified and ligated into NheI/XhoI-digested pCDNA3.1 (Invitrogen Corp., Carlsbad, California, USA) and used to transform Escherichia coli (DH5 $\alpha$ ). Plasmid DNA from several clones was isolated, purified, and the inserts fully sequenced. HEK 293 cells were transfected with normal and mutant CYP7A1 plasmids, and cholesterol $7 \alpha$-hydroxylase activity was measured, essentially using an established method (20). Cells were plated on day 1 at a density of $7 \times 10^{5}$ cells $/ 60-\mathrm{mm}$ plate. Cells were transfected on day 2 with $5 \mu \mathrm{g}$ DNA per plate using FuGENE 6 (Roche Molecular Biochemicals, Indianapolis, Indiana, USA) at a ratio of 2:3. Media was changed on day 3 to complete media containing $20 \mathrm{mg} / \mathrm{ml}$ 2-hydroxypropyl- $\beta$ cyclodextrin (Sigma-Aldrich, St. Louis, Missouri, USA). After 1 hour, $1.5 \mu \mathrm{Ci}\left[4-{ }^{14} \mathrm{C}\right]$-cholesterol $(53 \mathrm{mCi} / \mathrm{mmol}$; Amersham Pharmacia Biotech, Piscataway, New Jersey, USA) was added in $15 \mu$ l of ethanol. On day 4 , media was harvested and extracted with Folch reagent (chloroform/methanol, 2:1 vol/vol). Lipid extracts were purified on LK6DF TLC plates (Whatman Inc., Clifton, New Jersey, USA) developed in toluene/ethyl acetate 2:3 ( $\mathrm{vol} / \mathrm{vol})$ and exposed to $\mathrm{x}$-ray film (BIOMAX MS; Eastman Kodak Co., Rochester, New York, USA).

Bile acid and lipid analysis. Gas chromatography using the butyl ester method was used to measure levels of bile acid, sterol, and fatty acids in 24-hour stool samples and in urine and plasma $(21,22)$. Cholesterol and triglyceride content of lipoproteins, separated by ultracentrifugation, were determined by automated chemical analysis (23). Standards were provided by the Centers for Disease Control (Atlanta, Georgia, USA). Statistical analysis of LDL levels was by ANOVA. The subject selected to be a control for the stool analysis was chosen because he had a similar amount of lyophilized stool per day as the patient.

Hepatic enzyme activities. Hepatic microsomes and mitochondria were prepared by differential ultracentrifugation (24). Cholesterol concentrations in microsomes and mitochondria were determined by gas chromatography (25). Cholesterol $7 \alpha$-hydroxylase (EC 1.14.13.17) activity was measured by isotope incorporation $(24,26)$. The reaction $(0.5 \mathrm{ml})$ consisted of buffer $\left(100 \mathrm{mM} \mathrm{K}_{2} \mathrm{HPO}_{4}, 0.1 \mathrm{mM}\right.$ EDTA, $5 \mathrm{mM} \mathrm{DTT}, 30 \mathrm{mM}$ nicotinamide, $\mathrm{pH} 7.4),\left[4{ }^{14} \mathrm{C}\right]$ cholesterol $\left(5 \times 10^{5} \mathrm{dpm}\right)$ solubilized in $50 \mu \mathrm{l}$ of $25 \%$ (wt/vol) $\beta$-cyclodextrin, and $50-200 \mu \mathrm{g}$ microsomal protein. It was initiated with NADPH or an NADPH-generating system. $\left[{ }^{3} \mathrm{H}\right]$ $7 \alpha$-Hydroxycholesterol $\left(10^{4} \mathrm{dpm} / 5 \mu \mathrm{g}\right)$ was added as a recovery standard. After saponification, sterols were extracted, dissolved in $n$-hexane/2-propanol 


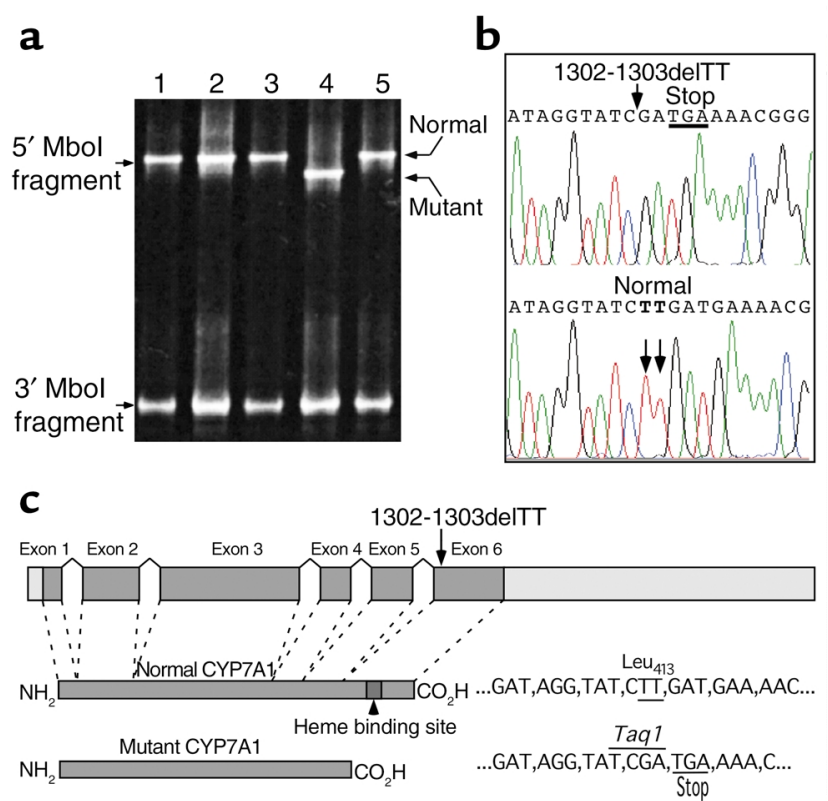

$(97: 3 \mathrm{vol} / \mathrm{vol})$, and applied to a silica column (500 mg, Sep-Pak; Waters Inc., Milford, Massachusetts, USA). After washing with $n$-hexane followed by $n$-hexane/ 2-propanol (97:3 vol/vol), $7 \alpha$-hydroxycholesterol was eluted with $n$-hexane $/ 2$-propanol ( $80: 20 \mathrm{vol} / \mathrm{vol})$. It was further isolated by TLC (Silica Gel 60; EM Science, Gibbstown, New Jersey, USA) and quantified by liquid scintillation counting.

\section{Figure 1}

Analysis of the CYP7A1 gene. (a) DGGE analysis of exon 6 showing the 1302-1303delTT mutation. Prior to DGGE, samples were digested with Mbol. Lanes 1, 2, 3, and 5, unaffected individuals; lane 4, subject IV-19. Normal homoduplex bands and mutant, gel-shifted homoduplex band are marked. (b) Sequence of a portion of exon 6 showing the TT deletion, which results in a frameshift and premature stop codon. (c) Diagrammatic depiction of the CYP7A1 gene structure with normal and predicted mutant proteins.

Sterol 27-hydroxylase (EC 1.14.13.15) activity was measured by an isotope incorporation method with consideration of endogenous cholesterol (26). Mitochondria were used as an enzyme source. An NADPH-generating system for mitochondria employing isocitrate dehydrogenase (27) was used. $\left[{ }^{3} \mathrm{H}\right]-27$-hydroxycholesterol was used as recovery standard. TLC plates were developed with a chloroform/methanol (94:6 vol/vol) solvent system.

HMG-CoA reductase (EC 1.1.1.34) activity was determined as described previously (27).

ApoE genotyping. The method described by Hixson and Vernier (28) was used to determine the apoE genotypes.

\section{Results}

Detection of CYP7A1 1302-1303delTT mutation. DGGE was used to screen for CYP7A1 gene mutations in patients with elevated LDL, including individuals with relative resistance to HMG-CoA reductase inhibitors, and in unselected control subjects. A unique pattern was seen for exon 6 in one sample, indicative of a a

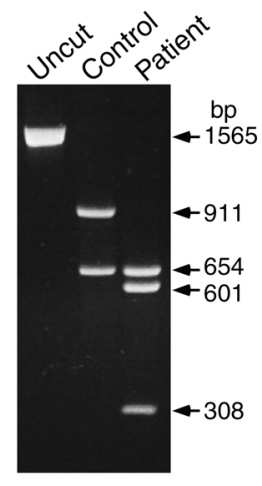

c 1

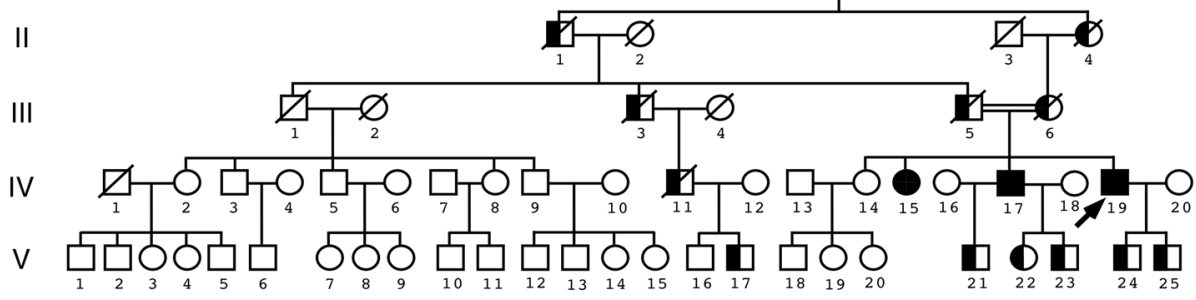

Figure 2

CYP7A1 mutation detection. (a) Taql digested full-length CYP7A1 cDNA produced by RT-PCR from control and patient (IV-17) RNA showing homozygosity for the additional Taql site. (b) Screening of the immediate family of the proband. Homozygotes are represented by filled squares and circles and heterozygotes by half-filled squares and circles. The coding region of exon 6 was amplified by PCR and digested with Taql. (The double horizontal lines indicate a consanguineous mating.) (c) Pedigree of family with CYP7A1 deficiency. Individuals II-1, II-4, III-3, III-5, III-6, and IV-11 are depicted as obligate carriers. *It cannot be inferred which one of these two subjects was the initial carrier. 
Table 1

Baseline lipid profiles (unadjusted for age and sex)

\begin{tabular}{|c|c|c|c|c|c|c|c|}
\hline Subject & $\begin{array}{c}\text { Age at } \\
\text { sampling }\end{array}$ & Sex & $\begin{array}{l}\text { CYP7A1 } \\
\text { genotype }\end{array}$ & $\begin{array}{c}\mathrm{TC} \\
(\mathrm{mg} / \mathrm{dl})\end{array}$ & $\begin{array}{c}\text { TG } \\
(\mathrm{mg} / \mathrm{dl})\end{array}$ & $\begin{array}{c}\text { LDL-C } \\
(\mathrm{mg} / \mathrm{dl})\end{array}$ & $\begin{array}{l}\text { HDL-C } \\
(\mathrm{mg} / \mathrm{dl})\end{array}$ \\
\hline $\mathrm{IV}-2$ & 80 & $\mathrm{~F}$ & $+/+$ & 240 & 227 & ND & ND \\
\hline IV-3 & 72 & M & $+/+$ & 227 & 180 & ND & ND \\
\hline IV-5 & 77 & M & $+/+$ & 274 & 277 & 165 & 59 \\
\hline IV-8 & 67 & $\mathrm{~F}$ & $+/+$ & 240 & 196 & 138 & 70 \\
\hline IV-9 & 79 & $M$ & $+/+$ & 185 & 53 & 101 & 80 \\
\hline IV-12 & 77 & $\mathrm{~F}$ & $+/+$ & 222 & 150 & 146 & 63 \\
\hline IV-14 & 60 & $\mathrm{~F}$ & $+/+$ & 258 & 130 & 158 & 83 \\
\hline IV-15 & 53 & $\mathrm{~F}$ & $-/-$ & 306 & 61 & 197 & 107 \\
\hline IV-17 & 56 & M & $-/-$ & 346 & 410 & 213 & 51 \\
\hline IV-18 & 50 & $\mathrm{~F}$ & $+/+$ & 192 & 47 & 111 & 79 \\
\hline IV-19 & 51 & M & $-1-$ & 419 & 919 & 151 & 29 \\
\hline IV-20 & 55 & $\mathrm{~F}$ & $+/+$ & 202 & 74 & 129 & 64 \\
\hline$V-1$ & 51 & M & $+/+$ & 289 & 179 & 186 & 80 \\
\hline$V-2$ & 49 & M & $+/+$ & 157 & 140 & 98 & 37 \\
\hline$V-3$ & 45 & $\mathrm{~F}$ & $+/+$ & 253 & 79 & 162 & 83 \\
\hline$V-4$ & 39 & $\mathrm{~F}$ & $+/+$ & 201 & 50 & 111 & 87 \\
\hline$V-5$ & 47 & M & $+/+$ & 199 & 150 & 122 & 45 \\
\hline$V-6$ & 33 & M & $+/+$ & 168 & 69 & 101 & 57 \\
\hline$V-7$ & 42 & $\mathrm{~F}$ & $+/+$ & 207 & 180 & 132 & 40 \\
\hline$V-8$ & 44 & $\mathrm{~F}$ & $+/+$ & 159 & 50 & 98 & 54 \\
\hline V-9 & 38 & $\mathrm{~F}$ & $+/+$ & 185 & 63 & 104 & 74 \\
\hline$V-10$ & 39 & $M$ & $+/+$ & 217 & 196 & 140 & 40 \\
\hline$V-11$ & 41 & $M$ & $+/+$ & 207 & 407 & 83 & 39 \\
\hline$V-12$ & 44 & $M$ & $+/+$ & 190 & 265 & 90 & 67 \\
\hline$V-13$ & 46 & $M$ & $+/+$ & 189 & 150 & 125 & 46 \\
\hline V-14 & 41 & $\mathrm{~F}$ & $+/+$ & 147 & 64 & 74 & 68 \\
\hline$V-15$ & 38 & $\mathrm{~F}$ & $+/+$ & 180 & 93 & 88 & 80 \\
\hline$V-16$ & 53 & $M$ & $+/+$ & 160 & 133 & 97 & 46 \\
\hline$V-17$ & 50 & $M$ & $+/-$ & 200 & 83 & 114 & 73 \\
\hline$V-18$ & 38 & $M$ & $+/+$ & 208 & 79 & 152 & 45 \\
\hline$V-19$ & 37 & $\mathrm{~F}$ & $+/+$ & 195 & 90 & 96 & 91 \\
\hline$V-20$ & 32 & F & $+/+$ & 188 & 183 & 87 & 75 \\
\hline$V-21$ & 29 & $M$ & $+/-$ & 214 & 186 & 132 & 48 \\
\hline$V-22$ & 17 & $\mathrm{~F}$ & $+/-$ & 163 & 44 & 102 & 58 \\
\hline$V-23$ & 13 & $M$ & $+/-$ & 185 & 210 & 112 & 44 \\
\hline$V-24$ & 18 & $M$ & $+/-$ & 183 & 99 & 125 & 43 \\
\hline$V-25$ & 13 & $M$ & $+/-$ & 202 & 98 & 142 & 47 \\
\hline
\end{tabular}

nucleotides 1302-1303, only one other difference: GAT at codon 347 replacing AAT in a published sequence (X56088). This was observed previously as a sequencing discrepancy (30). We detected this D347N polymorphism as an exon 4 DGGE variant (data not shown).

TaqI digestion of PCR-amplified exon 6 was used to screen relatives of the proband (Figure 2b). A brother (IV-17) and sister (IV-15) are also homozygous for this "knockout" mutation. The proband's parents were first cousins (Figure 2c). A total of three homozygotes and six heterozygotes were identified (Figure 2c). This mutation was not detected in 1,136 unrelated subjects: 720 hyperlipidemic patients and 416 unselected controls. DGGE analysis of DNA from the proband's sons (V-24 and V-25), both obligate heterozygotes, showed the expected homoduplex normal and mutant bands (data not shown). However, the pattern of heteroduplex bands was different, predicting an additional DNA variation. A common polymorphism was found in intron 5 (IVS5-108T>C) that accounted for these observations.

Transfection analysis of CYP7A1 mutation. Absence of cholesterol $7 \alpha$-hydroxylase activity was confirmed by transfection analysis of the mutant cDNA (Figure 3 ) in cultured HEK 293 cells, employing a routinely used method $(20,31)$. In contrast to the gene product of normal cDNA, no detectable activity was observed when cDNA containing the 1302-1303delTT mutation was studied.

Clinical history of CYP7A1-deficient patients. The 55-year-old proband (IV-19), a Caucasian of English and Celtic origin, was selected because his hyperlipidemia was homozygous variant (Figure 1a). A 2-bp deletion (13021303delTT; numbering of nucleotides in the cDNA is from the transcription start site) (29) in this patient's CYP7A1 gene resulted in a frameshift: L413fsX414 (Figure $1 \mathrm{~b}$ ). This mutation causes a Leu $\rightarrow$ Arg substitution at codon 413 followed immediately by a premature stop codon and results in a truncated protein lacking the C-terminal 91 residues (Figure 1c) with loss of the heme-binding domain, essential to activity. Thus, the mutant protein is predicted to be unable to hydroxylate cholesterol. To confirm that the deletion, which introduces a novel TaqI site, was maintained at the RNA level, we produced full-length cDNA by RT-PCR using RNA from a liver biopsy from the proband's brother (subject IV-17), who is also homozygous. TaqI digestion revealed the additional homozygous site (Figure 2a). Sequencing of the cDNA showed a normal splicing pattern and revealed, in addition to the TT deletion at resistant to HMG-CoA reductase inhibitors. He had presented with severe two-vessel coronary artery disease at age 48 and was subsequently found to have significant aortofemoral arteriosclerosis. Untreated, his serum cholesterol level was $419 \mathrm{mg} / \mathrm{dl}$ and triglycerides were 919 $\mathrm{mg} / \mathrm{dl}$ after a 10 -hour fast (Table 1 ). His body mass index (BMI) was 26.5. Analysis of his LDL fraction $(1.006-1.063 \mathrm{~g} / \mathrm{ml})$ revealed a ratio of cholesterol to triglycerides of 2.1 as compared with a mean value of $4.55 \pm 0.11( \pm \mathrm{SE})$ with nonselected control subjects $(n=345)$. This low value indicated the presence of remnant particles. His homozygous brother (IV-17) had a level of serum cholesterol of $346 \mathrm{mg} / \mathrm{dl}$ and triglycerides of $410 \mathrm{mg} / \mathrm{dl}$ (Table 1). He had a BMI of 28.9. At age 58 he remains free of symptomatic atherosclerotic disease. Both brothers underwent cholecystectomy for gallstones at ages 42 and 40, respectively. Gallstone disease is unusual in men at this age. Both are moderate drinkers 


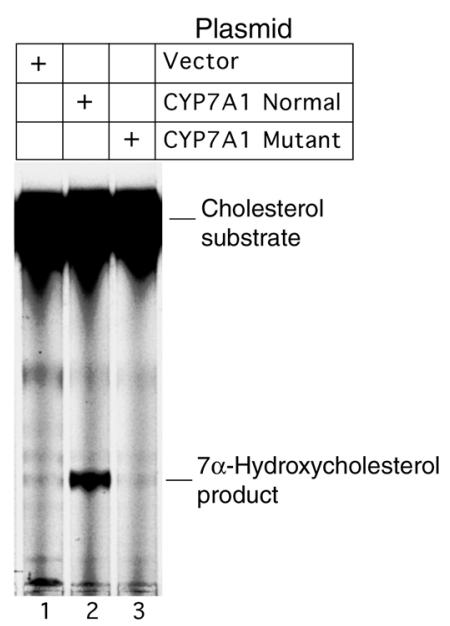

Figure 3

Expression of CYP7A1 in cultured HEK 293 cells showing absence of cholesterol 7- $\alpha$ hydroxylase activity in the L413fsX414 mutant. Cells were transfected with normal or mutant CYP7A1 plasmids (in pCDNA3.1) and incubated with $\left[4-{ }^{14} \mathrm{C}\right]$-cholesterol. Sterols extracted from the cell media were analyzed by TLC.

of alcohol and past smokers. Their hyperlipidemia is resistant to treatment. Only with a sustained combination of a powerful HMG-CoA reductase inhibitor, atorvastatin (80 $\mathrm{mg}$ and $40 \mathrm{mg}$ daily, respectively), together with niacin ( $6.5 \mathrm{~g}$ and $4.5 \mathrm{~g}$ daily, respectively), were their plasma levels of cholesterol and triglycerides brought under control. The most recent values for the proband (IV-19) were an LDL cholesterol level of $96 \mathrm{mg} / \mathrm{dl}$ and triglycerides of $166 \mathrm{mg} / \mathrm{dl}$. His brother had an LDL cholesterol level of $119 \mathrm{mg} / \mathrm{dl}$ and triglycerides of $108 \mathrm{mg} / \mathrm{dl}$.

Clinical investigation of a 54-year-old homozygous sister (BMI: 19.9) has been limited. She had levels of cholesterol of $306 \mathrm{mg} / \mathrm{dl}$ and triglycerides of $61 \mathrm{mg} / \mathrm{dl}$. A 60-year-old unaffected sister (BMI: 21.9) had a serum cholesterol level of $258 \mathrm{mg} / \mathrm{dl}$ and triglycerides of 130 $\mathrm{mg} / \mathrm{dl}$. This level of cholesterol is at the 79th percentile for her age (32). The total levels of cholesterol for each of the three homozygotes is above the 95th percentile for their ages (32). The three homozygotes and six heterozygotes all had the apo $E \varepsilon 3 / \varepsilon 3$ genotype.

When adjusted for age and sex, the increase in LDL in the three homozygotes was statistically significant compared with unaffected family members (Figure 4). The six heterozygotes had levels intermediate between the homozygotes and unaffected relatives, demonstrating a gene dosage effect (Figure 4). Adjusted levels of plasma HDL cholesterol were unaffected among carriers. Adjusted triglyceride levels for the heterozygotes $(156 \pm 42$ $\mathrm{mg} / \mathrm{dl} ; n=6$ ) were not significantly different from unaffected relatives $(123 \pm 13 \mathrm{mg} / \mathrm{dl} ; n=28)$. Both the proband and his brother had normal liver function tests. Liver biopsy done on patient IV-17 revealed mild focal macrovesicular fatty change with midzonal pallor of hepatocytes. No fibrosis or inflammation was observed. Bile acid analysis. The excretion of fecal bile acids in homozygote IV-17 (Table 2) was markedly deficient com- pared with a control sample, the values for which were similar to reported values (33). This was true for each of the five bile acid species measured present in a 24-hour stool sample. The total amount was $94 \%$ lower than the control. The ratio of cholic acid plus deoxycholic acid (derived from cholic acid by bacterial action in the gut) to chenodeoxycholic plus lithocholic acid plus ursodeoxycholic acid (both derived from chenodeoxycholic acid) was 0.46 , versus 1.41 for the control. Assuming steady state conditions, not only is much less bile acid being made, but also proportionately more chenodeoxycholic acid is being produced than cholic acid. This is consistent with synthesis via the alternative bile acid pathway (34). Table 2 also shows that compared with the control subject, more fat and less cholesterol was excreted. Because of this evidence of moderate fat malabsorption, we measured plasma levels of fat-soluble vitamins $\mathrm{A}$ and $\mathrm{E}$ in the two homozygous brothers and in two heterozygotes (V-22 and V-24). All levels of vitamin A were in the normal range with the exception of subject V-22. Her level was $28 \mu \mathrm{g} / \mathrm{dl}$ (normal range 38 to $98 \mu \mathrm{g} / \mathrm{dl}$ ). Except for the proband, whose vitamin E level was $41 \mathrm{mg} / \mathrm{l}$ and who takes 400 units daily, all other values were in the normal range $(5.7-19.9 \mathrm{mg} / \mathrm{l})$. Table 3 shows the plasma concentrations of bile acids in seven family members: three homozygotes, two heterozygotes, and two normal individuals. Though the total amounts do not show consistent differences, the fraction derived from chenodeoxycholic acid (chenodeoxycholic, ursodeoxycholic, and hyocholic acids) represents a high proportion of the total in the homozygous (IV-15, 48\%; IV-17, 70\%; IV-19, 79\%) and heterozygous (V-22, 67\%; $\mathrm{V}-23,71 \%$ ) subjects. That which was measured in normal individuals (IV-18 and IV-20) was all cholic acid derived. Only trace amounts of bile acids were seen in urine.

Plasma sterol analysis. In addition to hypercholesterolemia, increased levels of cholestanol ( $5 \alpha$-cholest- $3 \beta$ ol), 7-dehydrocholesterol, and plant sterols were found in plasma of the two homozygotes studied (Table 4).

Hepatic cholesterol level and enzyme activities. The cholesterol content of the liver from patient IV-17 was approximately $70 \%$ higher than controls (Table 5).

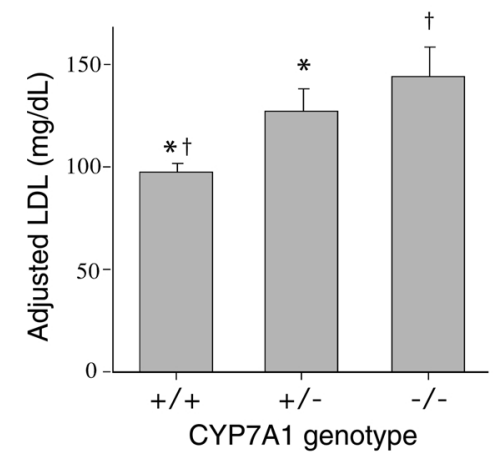

\section{Figure 4}

Plasma LDL analysis. Values were adjusted for age and sex and are means \pm SEM. Homozygotes $(-/-), n=3$; heterozygotes $(+/-), n=6$; unaffected relatives $(+/+), n=26 .{ }^{*} P=0.007 ;{ }^{\dagger} P=0.002$. Statistical analysis was by ANOVA. 
Table 2

Content of bile acids, sterols, and fatty acids in stool from a patient with CYP7A1 deficiency

\begin{tabular}{|c|c|c|c|c|c|c|c|c|c|c|c|}
\hline \multirow[b]{2}{*}{ Patient } & \multicolumn{8}{|c|}{$\begin{array}{l}\text { Stool bile acids } \\
\text { (mg/g dry weight) }\end{array}$} & \multirow[t]{2}{*}{$\begin{array}{l}\text { Sterols } \\
(\mathrm{mg} / \mathrm{g})\end{array}$} & \multirow[t]{2}{*}{$\begin{array}{l}\text { Fatty acids } \\
\qquad(\mathrm{mg} / \mathrm{g})\end{array}$} & \\
\hline & & LiCA & DCA & CDCA & CA & UDCA & $\mathrm{HCA}$ & Total & & & \\
\hline CYP7A1 & Genotype & & & & & & & & & & \\
\hline $\begin{array}{l}\text { IV-17 } \\
\text { (24-hour dried } \\
\text { stool: } 30.1 \mathrm{~g} \text { ) }\end{array}$ & $-/-$ & 0.44 & 0.19 & 0.05 & 0.07 & 0.08 & - & $\begin{array}{c}0.83 \\
(25.0)\end{array}$ & $\begin{array}{c}16.7 \\
(503)\end{array}$ & $\begin{array}{c}132.2 \\
(3978)\end{array}$ & $\mathrm{mg} / \mathrm{d}$ \\
\hline $\begin{array}{l}\text { Control }{ }^{\mathrm{A}} \\
\text { (24-hour dried } \\
\text { stool: } 33.3 \mathrm{~g} \text { ) }\end{array}$ & $+/+$ & 3.40 & 5.97 & 1.81 & 2.15 & 0.53 & - & $\begin{array}{c}13.86 \\
(461.5)\end{array}$ & $\begin{array}{c}34.6 \\
(1154)\end{array}$ & $\begin{array}{c}69.0 \\
(2298)\end{array}$ & $\mathrm{mg} / \mathrm{d}$ \\
\hline
\end{tabular}

However, there was little effect on HMG-CoA reductase activity. Cholesterol $7 \alpha$-hydroxylase activity was approximately $70 \%$ lower than controls, and sterol $27-$ hydroxylase (CYP27A1) activity was doubled (Table 5).

\section{Discussion}

When we selected CYP7A1 as a candidate gene, patient selection was based on a predicted phenotype such that there should be a high probability of finding mutations at that locus. We postulated that this phenotype could include, in addition to elevation of LDL cholesterol, resistance to treatment with HMG-CoA reductase inhibitors, premature cholesterol gallstone disease, and elevated triglycerides. We found a patient who was homozygous for an ablative mutation. The mutation, a 2-bp deletion (1302-1303delTT) causing a frameshift (L413fsX414), would result in loss of function, because the predicted protein truncation deletes the hemebinding domain. Expression of this mutant CYP7A1 cDNA in cultured HEK 293 cells confirmed the lack of cholesterol $7 \alpha$-hydroxylase activity.

The clinical phenotype of the three homozygotes in the kindred is striking and provides evidence for the critical role of CYP7A1 in whole body cholesterol homeostasis. The average total cholesterol level was above $300 \mathrm{mg} / \mathrm{dl}$ and LDL cholesterol above $180 \mathrm{mg} / \mathrm{dl}$. Also, the two male homozygotes have plasma levels of triglycerides that are substantially elevated. It was necessary to administer niacin along with atorvastatin to bring the elevated levels of cholesterol and triglycerides under control in these patients. Niacin is known to act by decreasing the rate of production of $\operatorname{VLDL}(35,36)$. A mechanism underlying the high level of LDL is suggested by the associated elevated liver cholesterol, which is due to decreased catabolism resulting from the low rate of bile acid production. The raised liver cholesterol leads to decreased proteolysis of membrane-associated SREBP and to its retention in the endoplasmic reticulum. The resulting decline in the active soluble form of this transcription factor causes downregulation of the LDL receptor gene. Reduced LDL receptor expression leads to lower hepatic clearance of both LDL and VLDL remnant particles. Analysis of the proband's LDL fraction indicated the presence of an abnormally high amount of such remnants. Delayed clearance of VLDL remnants leads to a greater proportion than normal being converted to LDL.

The two male homozygotes previously had undergone cholecystectomies. It is possible that the decreased secretion of bile acids in these patients may have resulted in unstable bile that was supersaturated with cholesterol and precipitation of cholesterol gallstones. Contributing to this effect, the increased cholesterol content of liver may have led to oxysterol activation of LXR/RXR and

Table 3

Concentration of plasma bile acids

\begin{tabular}{|c|c|c|c|c|c|c|c|c|}
\hline \multirow[b]{2}{*}{ Patient } & & \multicolumn{7}{|c|}{ Plasma bile acids $(\mu \mathrm{g} / \mathrm{ml})$} \\
\hline & & LiCA & DCA & CDCA & $\mathrm{CA}$ & UDCA & $\mathrm{HCA}$ & Total \\
\hline CYP7A1 & Genotype & & & & & & & \\
\hline $\begin{array}{l}\text { IV-15 } \\
\text { IV-17 } \\
\text { IV-19 }\end{array}$ & $\begin{array}{l}-/- \\
-/- \\
-/-\end{array}$ & $\begin{array}{l}- \\
- \\
-\end{array}$ & $\begin{array}{c}1.07 \\
2.30 \\
-\end{array}$ & $\begin{array}{c}0.30 \\
3.60 \\
-\end{array}$ & $\begin{array}{l}0.56 \\
1.10 \\
0.90\end{array}$ & $\begin{array}{l}0.74 \\
2.50 \\
1.90\end{array}$ & $\begin{array}{l}0.45 \\
1.80 \\
1.40\end{array}$ & $\begin{array}{c}3.12 \\
11.30 \\
4.20\end{array}$ \\
\hline $\begin{array}{l}V-22 \\
V-23\end{array}$ & $\begin{array}{l}+/- \\
+/-\end{array}$ & - & - & $\begin{array}{l}2.20 \\
4.50\end{array}$ & $\begin{array}{l}1.10 \\
1.80\end{array}$ & $\begin{array}{l}- \\
-\end{array}$ & - & $\begin{array}{l}3.30 \\
6.30\end{array}$ \\
\hline $\begin{array}{l}\text { IV-18 } \\
\text { IV-20 }\end{array}$ & $\begin{array}{l}+/+ \\
+/+\end{array}$ & - & $\begin{array}{c}9.80 \\
-\end{array}$ & - & $\begin{array}{l}4.10 \\
\text { Trace }\end{array}$ & - & - & $\begin{array}{l}13.90 \\
\text { Trace }\end{array}$ \\
\hline
\end{tabular}

LiCA, lithocholic acid ( $3 \alpha$-hydroxycholanoic acid); DCA, deoxycholic acid ( $3 \alpha, 12 \alpha$-dihydroxycholanoic acid); CDCA, chenodeoxycholic acid ( $3 \alpha, 7 \alpha$-dihydroxycholanoic acid); CA, cholic acid ( $3 \alpha, 7 \alpha, 12 \alpha$-trihydroxycholanoic acid); UDCA, ursodeoxycholic acid (3 $\alpha, 7 \beta$-dihydroxycholanoic acid); HCA, hyocholic acid $(3 \alpha, 6 \alpha, 7 \alpha$-trihydroxycholanoic acid). 
Table 4

Plasma sterol analysis of two patients with CYP7A1 deficiency

\begin{tabular}{lcccccc} 
Patient & & & \multicolumn{3}{c}{ Sterol (mg/dl) } \\
& CYP7A1Genotype & Cholesterol & Cholestanol & 7-Dehydrocholesterol & Campesterol $^{\text {Sitosterol }}$ \\
IV-17 & $-/-$ & 245 & 1.23 & 0.49 & 0.69 & 1.38 \\
IV-19A $^{\text {A }}$ & $-/-$ & 171 & 0.80 & 0.24 & 0.90 & 0.65 \\
Controls $^{\mathrm{B}}(20)$ & $+/+$ & $195 \pm 37$ & $0.20 \pm 0.20$ & Trace & Trace & $0.20 \pm 0.20$
\end{tabular}

AThe patients were on lipid-lowering drugs when these samples were obtained. Both were taking high doses of HMG-CoA reductase inhibitors and subject IV-19 was also taking niacin $6.5 \mathrm{~g} /$ day. ${ }^{\mathrm{B}}$ Controls were 20 healthy individuals (ten men and ten women aged 28 to 65 ). ${ }^{\mathrm{C}} 5 \alpha-\mathrm{Cholest}-3 \beta$-ol. ${ }^{\mathrm{D}} \mathrm{Cholest-5,7-}$

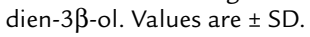

induction of secretion of cholesterol into bile via transactivation of ABCG5/G8 (37). The homozygous sister has not been evaluated for asymptomatic gallstones.

The elevated triglycerides in the two homozygous brothers may reflect a long-recognized, but very poorly understood, relationship between bile acid biosynthesis and triglyceride production $(38,39)$. The presence of hypertriglyceridemia here would be consistent with a number of studies that show a reciprocal relationship between bile acids and triglycerides. Compared with control subjects, hypertriglyceridemic patients recently were shown to have decreased levels of ileal apical sodium bile acid transporter mRNA and protein, resulting in impaired bile acid absorption (40). Subjects taking bile acid-binding resins have elevated production of VLDL triglycerides (41). In a rat hepatocyte model system it was shown that addition of taurocholate resulted in decreased VLDL secretion $(42,43)$. However, in the CYP7A1 knockout mouse model, the animals have decreased bile acid production but are normotriglyceridemic $(15,16)$. In humans, treatment with chenodeoxycholic acid has been shown to reduce hypertriglyceridemia $(44,45)$. Furthermore, there is accumulating evidence that the production of certain apolipoproteins is regulated by the bile acid-activated nuclear receptor FXR (farnesoid X receptor) $(46,47)$. Expressed mainly in the liver, apolipoprotein C-II (apoC-II) is a requisite cofactor for lipoprotein lipase. Because FXR induces transcription of the apoC-II gene (46), a possible additional mechanism linking plasma levels of triglycerides with bile acid concentrations in the liver is suggested, in addition to any effect of bile acids on the synthesis of VLDL.

The fecal bile acid excretion measured at $6 \%$ of normal in a homozygous male is consistent with loss of CYP7A1 activity. This decrease is greater than the $59 \%$ seen with CYP7A1 homozygous null mice (48). In that study, bile acid pool size was measured and was $79 \%$ lower than in the wild-type animals. The composition of fecal bile acids from subject IV-17 is consistent with a proportionately higher rate of chenodeoxycholic acid synthesis relative to that of cholic acid. This observation is supported by the plasma bile acid compositions. As indicated by the doubling of CYP27A1 activity, it is accounted for by upregulation of the alternative pathway (34) in which 27-hydroxycholesterol formed in mitochondria via the CYP27A1 gene product is converted to cholest-5-ene-3 $\beta, 7 \alpha, 27$-triol by oxysterol $7 \alpha$-hydroxylase (product of the CYP7B1 gene). It is known that when the neutral pathway is downregulated by repression of CYP7A1, the alternative pathway is still capable of yielding bile acids that are $7 \alpha$-hydroxylated (7). A doubling of CYP27A1 activity and upregulation of the alternative pathway was reported with CYP7A1-/- mice (49). However, induction of the alternative pathway that yields mainly chenodeoxycholic acid, though capable of forming some cholic acid, was not adequate in subject IV-17 to metabolize the excess hepatic cholesterol. The stool analysis revealed that more fat was excreted relative to cholesterol. Although cholesterol and fat (monoglyceride and free fatty acids) are dissolved in the bile acid micelles prior to absorption, the mechanisms of absorption are different. Moreover, a lot more fat is absorbed than cholesterol. Thus, the apparent normal cholesterol absorption is not inconsistent with moderate fat malabsorption in this patient where bile acid synthesis is reduced, and the intestinal bile acid pool is probably small. The moderate fat malabsorption was not reflected by fat-soluble vitamin $A$ and $E$ deficiency in plasma in this individual or his homozygous brother. This is in contrast to CYP7A1-/mice that had low serum levels of vitamin E, especially before weaning (15). Though these animals displayed severe lipid malabsorption before weaning, older animals had a more normal content of fecal lipid. The low vitamin A level in a heterozygous 17-year-old girl is somewhat enigmatic, unless her dietary intake is insufficient.

Table 5

Hepatic enzyme activities and cholesterol content in a patient with CYP7A1 deficiency

\begin{tabular}{|c|c|c|c|c|c|}
\hline \multirow[t]{2}{*}{ Patient } & \multirow[b]{2}{*}{ CYP7A1Genotype } & \multicolumn{3}{|c|}{ Hepatic enzyme activities (pmol/mg microsomal protein/min) } & \multirow{2}{*}{$\begin{array}{l}\text { Hepatic cholesterol } \\
\text { (nmol/mg protein) }\end{array}$} \\
\hline & & Cholesterol $7 \alpha$-hydroxylase & Sterol 27-hydroxylase & HMG-CoA reductase & \\
\hline $\mathrm{IV}-17^{\mathrm{A}}$ & $-/-$ & 6.3 & 44.2 & 57.6 & 40.1 \\
\hline Controls $^{B}(3)$ & $+/+$ & $20.3 \pm 0.5$ & $21.5 \pm 1.2$ & $69.1 \pm 4.5$ & $23.4 \pm 0.9$ \\
\hline
\end{tabular}

AThe patient had not taken lipid-lowering drugs for 3 weeks prior to the biopsy. ${ }^{\mathrm{B} C}$ Controls were three healthy men aged 37,48 , and 57 years, who died unexpectedly in auto accidents. Values are \pm SEM. 
Although we showed that the mutated CYP7A1 gene did not produce an active protein in vitro, some cholesterol $7 \alpha$-hydroxylase activity was present in the liver biopsy from patient IV-17. Nonetheless, activity was $70 \%$ lower than controls despite doubling of CYP27A1 activity. The presence of measurable cholesterol $7 \alpha$-hydroxylase activity contrasts with reports that livers from CYP7A1 null mice had no cholesterol $7 \alpha$-hydroxylase activity $(48,50)$. The source of activity in the patient's liver is unclear. It has been emphasized that the CYP7B1 enzyme is unable to hydroxylate cholesterol (48), its preferred substrate being 27-hydroxycholesterol and its oxidation product $3 \beta$-hydroxy-5-cholestenoic acid $(12,34)$. In humans, an additional enzyme may be present. Whether this could be the recently described CYP39A1 gene product, a 24 -hydroxysterol $7 \alpha$-hydroxylase, is not clear because activity toward cholesterol per se was not reported (31).

CYP7B1 is important in the human neonate for the production of bile acids (7). Deficiency is associated with fatal neonatal liver disease due to accumulation of toxic abnormal bile acids (51). CYP7A1 could not compensate, its activity being very low in the patient with CYP7B1 deficiency as well as in normal infants. Survival of the three homozygotes in the present study points to lack of severe neonatal disease associated with CYP7A1 deficiency. Apparently, production of bile acids by the alternative pathway using CYP7B1 is sufficient to maintain viability in the neonatal period. In contrast to humans, CYP7A1 deficiency in the mouse has been reported to result in the perinatal death of approximately $90 \%$ of the CYP7A1-/- pups unless their diet is supplemented with vitamins and cholic acid (50). In these animals serum levels of lipid and lipoproteins were unaffected compared with the wild-type mice. Another colony of mice, bred out from the first knockout line, displayed a high pup survival rate in the absence of chow supplementation and decreased fecal bile acids and had hypercholesterolemia (16).

The elevated level of cholestanol in plasma of the two homozygous patients that we studied is consistent with decreased cholesterol $7 \alpha$-hydroxylase activity. Cholestanol, synthesized in liver, is an efficient substrate for cholesterol $7 \alpha$-hydroxylase (52). The elevated levels in plasma of 7-dehydrocholesterol, an intermediate in cholesterol biosynthesis, are possibly a reflection of increased cholesterol synthesis. However, 7-dehydrocholesterol was measured when the patients were taking HMG-CoA reductase inhibitors, and de novo synthesis would be expected to be suppressed. Levels of 7-dehydrocholesterol and HMG-CoA reductase activity are strongly correlated (53), and lovastatin treatment in rats is associated with undetectable levels of 7-dehydrocholesterol (54). Thus, the elevated levels of 7-dehydrocholesterol are enigmatic. The moderately elevated levels of plant sterols (campesterol and sitosterol) in plasma may indicate increased intestinal sterol absorption. However, the indication of normal cholesterol absorption argues against this. Another explanation lies in the elevated cholesterol content of liver. The liver can defend itself to some extent against an accumulation of sterols by excreting them into the bile (probably by ABCG5/G8). If this process is saturated, competition between cholesterol and plant sterols might result in hepatic retention of plant sterols.

In addition to decreased classic bile acid synthesis, the human CYP7A1 mutation results in substantial cholesterol accumulation in the liver. This contrasts with observations in CYP7A1 null mice, which showed no accumulation (48). Given the increase in hepatic cholesterol in human CYP7A1 deficiency, it is surprising that the activity of HMG-CoA reductase was not greatly affected. Though a direct correlation between the activities of HMG-CoA reductase and cholesterol $7 \alpha$-hydroxylase exists under many circumstances, it was not seen in cholesterol-fed rats (55). Also, the CYP7A1 gene does not have the same expression pattern in liver as reductase. The former is more highly expressed in the proximal perivenous cells $(56,57)$ and the latter in cells of periportal lobular zones (58). The limited effect on HMG-CoA reductase seen here could reflect altered compartmentalization of a critical sterol regulatory pool.

Four monogenic disorders with elevated levels of LDL result from mutations at gene loci for the LDL receptor, apoB-100, ARH, and ABCG5/ABCG8 (1). To this quartet of disorders now can be added familial cholesterol $7 \alpha$-hydroxylase deficiency. This appears to be an autosomal codominant disorder. Heterozygotes had an average LDL cholesterol level, adjusted for age and sex, that was $30 \mathrm{mg} / \mathrm{dl}$ higher than that of their unaffected relatives. Because the phenotype is expressed in the heterozygous state, mutations in the CYP7A1 gene could contribute to the prevalence of atherogenic hyperlipidemia and susceptibility to cholesterol gallstone disease in the population.

\section{Acknowledgments}

The authors wish to acknowledge the generous participation of members of the affected kindred and the able assistance of Nancy E. Witman in the collection of blood samples. This work was supported by NIH grants HL-50782, HL-50779, and DK-26756; by American Heart Association, Western States Affiliates Grant-in-Aid 98-212 and American Heart Association, National 0150571N; and by gifts from the Joseph Drown Foundation, the Donald T. and Rachel C. Valentine Foundation, Donald Yellon, and Donald and Susan Schleicher. Merit awards from the Department of Veterans Affairs supported S.K. Erickson and G. Salen. These studies were carried out, in part, in the General Clinical Research Center, Moffitt Hospital, University of California, San Francisco, with funds provided by the National Center for Research Resources, 5 MO1 RR-00079, U.S. Public Health Service. Normal liver tissue was obtained under NIH contract 1-DK62274.

\footnotetext{
1. Goldstein, J.L., and Brown, M.S. 2001. Molecular medicine. The cholesterol quartet. Science. 292:1310-1312.

2. Goldstein, J.L., Hobbs, H.H., and Brown, M.S. 2001. Familial hypercholesterolemia. In The metabolic and molecular bases of inherited disease. Vol. II. C.R Scriver, A.L. Beaudet, W.S. Sly, and D. Valle, editors. McGraw-Hill. New York, New York, USA. 2863-2913.
} 
3. Kane, J.P., and Havel, R.J. 2001. Disorders of the biogenesis and secretion of lipoproteins containing the B-apolipoproteins. In The metabolic and molecular bases of inherited disease. Vol. II. C.R. Scriver, A.L. Beaudet, W.S. Sly, and D. Valle, editors. McGraw-Hill. New York, New York, USA. 2717-2752.

4. Garcia, C.K., et al. 2001. Autosomal recessive hypercholesterolemia caused by mutations in a putative LDL receptor adaptor protein. Science. 292:1394-1398.

5. Berge, K.E., et al. 2000. Accumulation of dietary cholesterol in sitosterolemia caused by mutations in adjacent $\mathrm{ABC}$ transporters. Science. 290:1771-1775.

6. Lee, M.H., et al. 2001. Identification of a gene, ABCG5, important in the regulation of dietary cholesterol absorption. Nat. Genet. 27:79-83.

7. Schwarz, M., Lund, E.G., and Russell, D.W. 1998. Two 7 $\alpha$-hydroxylase enzymes in bile acid biosynthesis. Curr. Opin. Lipidol. 9:113-118.

8. Nishimoto, M., Noshiro, M., and Okuda, K. 1993. Structure of the gene encoding human liver cholesterol $7 \alpha$-hydroxylase. Biochim. Biophys. Acta. 1172:147-150.

9. Cohen, J., et al. 1992. Cloning of the human cholesterol-7 $\alpha$-hydroxylase gene (CYP7) and localization to chromosome 8q11-q12. Genomics. 14:153-161.

10. Wang, J., et al. 1998. Linkage between cholesterol $7 \alpha$-hydroxylase and high plasma low-density lipoprotein cholesterol concentrations. J. Clin. Invest. 101:1283-1291.

11. Couture, P., et al. 1999. Association of the A-204C polymorphism in the cholesterol $7 \alpha$-hydroxylase gene with variations in plasma low density lipoprotein cholesterol levels in the Framingham Offspring Study. J. Lipid Res. 40:1883-1889.

12. Cohen, J.C. 1999. Contribution of cholesterol $7 \alpha$-hydroxylase to the regulation of lipoprotein metabolism. Curr. Opin. Lipidol. 10:303-307.

13. Spady, D.K., Cuthbert, J.A., Willard, M.N., and Meidell, R.S. 1995. Adenovirus-mediated transfer of a gene encoding cholesterol $7 \alpha$-hydroxylase into hamsters increases hepatic enzyme activity and reduces plasma total and low density lipoprotein cholesterol. J. Clin. Invest. 96:700-709.

14. Miyake, J.H., et al. 2002. Transgenic expression of cholesterol-7 $\alpha$-hydroxylase prevents atherosclerosis in C57BL/6J mice. Arterioscler. Thromb. Vasc. Biol. 22:121-126.

15. Schwarz, M., et al. 1996. Disruption of cholesterol $7 \alpha$-hydroxylase gene in mice. II. Bile acid deficiency is overcome by induction of oxysterol $7 \alpha$ hydroxylase. J. Biol. Chem. 271:18024-18031.

16. Erickson, S.K., et al. 1999. Effect of cholesterol $7 \alpha$-hydroxylase (CYP7A) gene knockout on lipid homeostasis. Circulation. 100:I-686-I-687. (Abstr.)

17. Pullinger, C.R., et al. 1995. Familial ligand-defective apolipoprotein B identification of a new mutation that decreases LDL receptor binding affinity. J. Clin. Invest. 95:1225-1234.

18. Pullinger, C., et al. 1999. The apolipoprotein B R3531C mutation. Characteristics of 24 subjects from 9 kindreds. J. Lipid Res. 40:318-327.

19. Duchateau, P., Pullinger, C., Cho, M., Eng, C., and Kane, J. 2001. Apolipoprotein L gene family. Tissue-specific expression, splicing, promoter regions; discovery of a new gene. J. Lipid Res. 42:620-630.

20. Schwarz, M., et al. 2000. The bile acid synthetic gene $3 \beta$-hydroxy- $\Delta^{5}-C_{27}$ steroid oxidoreductase is mutated in progressive intrahepatic cholestasis. J. Clin. Invest. 106:1175-1184.

21. Batta, A.K., et al. 1999. Highly simplified method for gas-liquid chromatographic quantitation of bile acids and sterols in human stool. J. Lipid Res. 40:1148-1154.

22. Batta, A.K., and Salen, G. 1999. Gas chromatography of bile acids. J. Chromatogr. B. Biomed. Appl. 723:1-16.

23. Kane, J.P., et al. 1990. Regression of coronary atherosclerosis during treatment of familial hypercholesterolemia with combined drug regimens. JAMA. 264:3007-3012.

24. Shefer, S., Salen, G., and Batta, A.K. 1986. Cholesterol $7 \alpha$-hydroxylase ( $7 \alpha-$ monooxygenase EC1.14.13.17). In Methods of assay. R. Fears and J.R. Sabine, editors. CRC Press. Boca Raton, Florida, USA. 43-49.

25. Xu, G., et al. 1995. Unexpected inhibition of cholesterol $7 \alpha$-hydroxylase by cholesterol in New Zealand White and Watanabe heritable hyperlipidemic rabbits. J. Clin. Invest. 95:1497-1504.

26. Honda, A., et al. 1999. Bile acid synthesis in the Smith-Lemli-Opitz syndrome: effects of dehydrocholesterols on cholesterol $7 \alpha$-hydroxylase and 27-hydroxylase activities in rat liver. J. Lipid Res. 40:1520-1528.

27. Nicolau, G., Shefer, S., Salen, G., and Mosbach, E.H. 1974. Determination of hepatic 3-hydroxy-3-methylglutaryl CoA reductase activity in man. $J$. Lipid Res. 15:94-98.

28. Hixson, J.E., and Vernier, D.T. 1990. Restriction isotyping of human apolipoprotein $\mathrm{E}$ by gene amplification and cleavage with HhaI.J. Lipid Res. 31:545-548.

29. Molowa, D.T., Chen, W.S., Cimis, G.M., and Tan, C.P. 1992. Transcriptional regulation of the human cholesterol $7 \alpha$-hydroxylase gene. Biochemistry. 31:2539-2544

30. Karam, W.G., and Chiang, J.Y.L. 1992. Polymorphisms of human cholesterol $7 \alpha$-hydroxylase. Biochem. Biophys. Res. Commun. 185:588-595.

31. Li-Hawkins, J., Lund, E.G., Bronson, A.D., and Russell, D.W. 2000. Expression cloning of an oxysterol $7 \alpha$-hydroxylase selective for 24-hydroxycholesterol. J. Biol. Chem. 275:16543-16549.
32. U.S. Department of Health and Human Services. 1980. Lipid research clinics population studies data book. Vol. I. The prevalence study. U.S. Department of Health and Human Services, Public Health Service, National Institutes of Health (NIH publication number 80-1527), Washington, DC, USA

33. Mok, H.Y., von Bergmann, K., and Grundy, S.M. 1979. Effects of continuous and intermittent feeding on biliary lipid outputs in man: application for measurements of intestinal absorption of cholesterol and bile acids. $J$. Lipid Res. 20:389-398.

34. Vlahcevic, Z.R., Pandak, W.M., and Stravitz, R.T. 1999. Regulation of bile acid biosynthesis. Gastroenterol. Clin. North Am. 28:1-25.

35. Langer, T., and Levy, R.I. 1970. Effect of nicotinic acid on beta lipoprotein metabolism. Clin. Res. 18:458. (Abstr.)

36. Levy, R.I., and Langer, T. 1972. Hypolipidemic drugs and lipoprotein metabolism. Adv. Exp. Med. Biol. 26:155-163.

37. Edwards, P.A., Kast, H.R., and Anisfeld, A.M. 2002. BAREing it all: the adoption of LXR and FXR and their roles in lipid homeostasis. J. Lipid Res. 43:2-12.

38. Angelin, B., Einarsson, K., Hellström, K., and Leijd, B. 1978. Bile acid kinetics in relation to endogenous triglyceride metabolism in various types of hyperlipoproteinemia. J. Lipid Res. 19:1004-1016.

39. Angelin, B., Eriksson, M., and Rudling, M. 1999. Bile acids and lipoprotein metabolism: a renaissance for bile acids in the post-statin era? Curr. Opin. Lipidol. 10:269-274.

40. Duane, W.C., Hartich, L.A., Bartman, A.E., and Ho, S.B. 2000. Diminished gene expression of ileal apical sodium bile acid transporter explains impaired absorption of bile acid in patients with hypertriglyceridemia. J. Lipid Res. 41:1384-1389.

41. Beil, U., Crouse, J.R., Einarsson, K., and Grundy, S.M. 1982. Effects of interruption of the enterohepatic circulation of bile acids on the transport of very low density-lipoprotein triglycerides. Metabolism. 31:438-444.

42. del Pozo, R, and Barth, C.A. 1987. Bile acids inhibit secretion of very low density lipoprotein by rat hepatocytes. Biol. Chem. Hoppe Seyler. 368:887-893.

43. Lin, Y., et al. 1996. Characterization of the inhibitory effects of bile acids on very-low-density lipoprotein secretion by rat hepatocytes in primary culture. Biochem. J. 316:531-538.

44. Bateson, M.C., Maclean, D., Evans, J.R., and Bouchier, I.A. 1978. Chenodeoxycholic acid therapy for hypertriglyceridaemia in men. Br.J. Clin. Pharmacol. 5:249-254.

45. Carulli, N., et al. 1981. Chenodeoxycholic acid and ursodeoxycholic acid effects in endogenous hypertriglyceridemias. A controlled double-blind trial. J. Clin. Pharmacol. 21:436-442.

46. Kast, H.R., et al. 2001. Farnesoid X-activated receptor induces apolipoprotein C-II transcription: a molecular mechanism linking plasma triglyceride levels to bile acids. Mol. Endocrinol. 15:1720-1728.

47. Claudel, T., et al. 2002. Bile acid-activated nuclear receptor FXR suppresses apolipoprotein A-I transcription via a negative FXR response element. J Clin. Invest. 109:961-971. doi:10.1172/JCI200214505.

48. Schwarz, M., Russell, D.W., Dietschy, J.M., and Turley, S.D. 1998. Marked reduction in bile acid synthesis in cholesterol $7 \alpha$-hydroxylase-deficient mice does not lead to diminished tissue cholesterol turnover or to hypercholesterolemia. J. Lipid Res. 39:1833-1843

49. Shefer, S., Erickson, S.K., Lear, S.R., Batta, A.K., and Salen, G. 2000. Upregulation of hepatic cholesterol 27-hydroxylase (CYP27) activity and normal levels of hepatic cholesterol synthesis in cholesterol 7A-hydroxylase (CYP7A1) gene knockout mice. Gastroenterology. 118:A998. (Abstr.)

50. Ishibashi, S., Schwarz, M., Frykman, P.K., Herz, J., and Russell, D.W. 1996. Disruption of cholesterol $7 \alpha$-hydroxylase gene in mice. I. Postnatal lethality reversed by bile acid and vitamin supplementation. J. Biol. Chem. 271:18017-18023.

51. Setchell, K.D., et al. 1998. Identification of a new inborn error in bile acid synthesis: mutation of the oxysterol $7 \alpha$-hydroxylase gene causes severe neonatal liver disease. J. Clin. Invest. 102:1690-1703.

52. Myant, N. 1981. The biology of cholesterol and related steroids. Heinemann. London, United Kingdom. 241 pp.

53. Axelson, M., Angelin, B., Hillebrant, C.G., Reihnér, E., and Einarsson, C. 1998. The level of 7-dehydrocholesterol in plasma reflects the activity of 3hydroxy-3-methylglutaryl coenzyme A reductase in the human liver. Biochim. Biophys. Acta. 1394:153-157.

54. Amin, D., et al. 1997. RPR 107393, a potent squalene synthase inhibitor and orally effective cholesterol-lowering agent: comparison with inhibitors of HMG-CoA reductase. J. Pharmacol. Exp. Ther. 281:746-752.

55. Myant, N.B., and Mitropoulos, K.A. 1977. Cholesterol $7 \alpha$-hydroxylase. J. Lipid Res. 18:135-153.

56. Brassil, P.J., Edwards, R.J., and Davies, D.S. 1995. Expression and distribution of cholesterol $7 \alpha$-hydroxylase in rat liver. Biochem. Pharmacol. 50:311-316

57. Massimi, M., Lear, S.R., Huling, S.L., Jones, A.L., and Erickson, S.K. 1998 Cholesterol $7 \alpha$-hydroxylase (CYP7A): patterns of messenger RNA expression during rat liver development. Hepatology. 28:1064-1072.

58. Singer, I.I., et al. 1984. Hydroxymethylglutaryl-coenzyme A reductase-containing hepatocytes are distributed periportally in normal and mevinolintreated rat livers. Proc. Natl. Acad. Sci. USA. 81:5556-5560. 